\section{BRITISH RUBBER PRODUCERS' RESEARCH ASSOCIATION}

\section{REPORT FOR 1956}

$T$ HE research interest in high polymers having industrial uses is very great in this post-war world and the subject has achieved, or almost achieved, academic respectability. Excluding the fibre-forming polymers, which are very adequately catered for in Britain with three research associations and at least two university departments, non-commercial research (namely, that carried out by bodies independent of the commercial interests of a given company) is unevenly distributed over the field of interest. Britain has nothing approaching the T.N.O. Instituut connected with the University of Delft in which studies are being made over the whole field of high polymers, their technical properties and applications. Thus, in Britain, no research association serves the thermosetting plasties industry, and thermoplastics, though largely used by rubber manufacturing companies, are only dealt with unofficially and inadequately.

In contrast with this, the earliest known of the high polymers, natural rubber, has an organization devoted exclusively to its study, besides being one of the main subjects of a research association sponsored by the Department of Scientific and Industrial Research. 'The British Rubber Producers' Research Association is not so sponsored, but has been, and is, financed solely by a cess raised on rubber exported from British-controlled territories producing rubber. This is now changing: Ceylon has become an independent member of the Commonwealth, and the current annual report of the British Rubber Producers' Research Association* will be the last dealing with work financed before the independence of Malaya

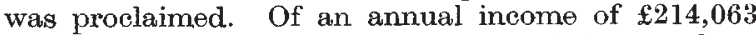
from all sources, approximately $£ 205,000$ came from the east, including $£ 183,000$ from Malaya. This represents a considerably greater investment in research than the income that the Research Association of British Rubber Manufacturers derives from the industry in Britain (about $£ 50,000$ of a total income of $£ 91,000$ ).

The research work of the British Rubber Producers' Research Association is summarized by the director of research, Dr. L. Bateman, in a report consisting of twenty-six pages (including a number of figures and photographs) of technical summary, easily assimilated by the non-specialist reader and emphasizing ends rather than means. Considerable effort is being made to use natural rubber not only as a material in its own right, but also as the raw material from which other high polymers having different properties can be made. Graft polymerization has been studied, a variety of radical additions to the main chain molecules of the rubber being initiated either by highenergy radiation or by the utilization of one of the Association's own discoveries. When rubber is milled in the ordinary course of factory processing, the molecule of high molecular weight is mechanically sheared, two ends being created from the centre of the broken hydrocarbon chain. These two ends are free radicals which normally attack some other

* British Rubber Producers' Research Association. Nineteenth Annual Report, 1956. Pp. 44. (London: British Rubber Producers' Research Association, 1957.) molecule or are 'quenched' by atmospheric oxygen. They can equally well, in the absence of oxygen, be used for initiating the polymerization of other active monomeric materials if these are present, and thus comes about an ingenious method of grafting one molecular species on to another. The difficult composite properties of tearing and abrasion are also being actively studied in the physics department, and with the aid of electron microscope studies of replicas of the torn surfaces, the structure at the growing tip of a tear has been examined, not merely for a pure gum rubber, but for vulcanizates loaded with filler particles such as the carbon black used in re-inforcing tyre-tread rubbers.

All this and other work has been published for the free use of the world in a further twenty-four papers in the journals of various learned societies, bringing the total of communications to 241. No other series of papers can have done more than this series in bringing high-polymer studies to the academic rank they now occupy; whether it can assure natural rubber a permanent place in the scheme of things is another matter, but that it has given the natural product a better chance of survival in a man-made world cannot be doubted.

W. C. WAKE

\section{COMMONWEALTH OF AUSTRALIA SCIENTIFIC AND INDUSTRIAL RESEARCH ORGANIZATION}

\section{REPORT FOR 1955-56}

WE eighth annual report of the Commonwealth of Australia Scientific and Industrial Research Organization* covers the year ended June 30, 1956, in which expenditure was $£ 6,266,234$, of which $£ 4,716,313$ was on normal research activities, $£ 100,431$ on grants to the Commonwealth Agricultural Bureaux and like bodies, $£ 10,738$ on eapital works and the remainder on investigations financed from contributions, which included $£ 873,451$ from the Wool Research Trust Account and £317,885 from the Wool Industry Fund. Besides details of personnel of the Council, committees and staff, the report contains a list of papers and patents published during the year. Reference is made to the inereasing cost of equipment and the need for financial provision to keep equipment up to date if first-class research workers are to be retained. A permanent Patents Committee has now been established to examine proposals for patents, to review current patents periodically and to decide on the best method of exploiting the Organization's patents for the benefit of the Commonwealth. A contract has been let for a design study for the giant radio telescope, towards which the Radio Astronomy Trust has now more than $£ 520,000$ in sight.

Reconnaissance examinations were made of soils in the far north-west of South Australia for comparison with the soils and landscape previously studied at Yudnapinna in the north-west pastoral country : it is hoped that these investigations will assist the solution of some pedological problems there and lead to a better understanding of this arid part of Australia. In field work in the south-east region more emphasis

* Eighth Annual Report of the Commonwealth Scientific an Industrial Annal Reort of the cor the year 1955-1956. Pp. 180. Industrial Research Organization for the year 1 